06.1

\title{
Свойства оптических керамик КО1 и КО2 при модификации их поверхности углеродными нанотрубками
}

\author{
() Н.В. Каманина ${ }^{1,2}$, С.В. Лихоманова ${ }^{1}$, Ю.Р. Загидуллина ${ }^{3}$ \\ ${ }^{1}$ АО „Государственный оптический институт им. С.И. Вавилова“, Санкт-Петербург, Россия \\ ${ }^{2}$ Санкт-Петербургский государственный электротехнический университет „ЛЭТИ“, Санкт-Петербург, Россия \\ ${ }^{3}$ Башкирский государственный университет, Уфа, Россия \\ E-mail: nvkamanina@mail.ru
}

Поступило в Редакцию 11 апреля 2019г.

В окончательной редакции 29 апреля 2019г.

Принято к публикации 29 апреля 2019г.

Представлены результаты исследований модификации свойств оптических неорганических материалов: оптической керамики КО1 $\left(\mathrm{MgF}_{2}\right)$ и КО2 $(\mathrm{ZnS})$. Обнаружено существенное изменение основных характеристик данных неорганических матриц, поверхность которых модифицирована углеродными нанотрубками при применении лазерного ориентированного метода осаждения. Учтены основные особенности углеродных нанотрубок, обусловленные их развитой поверхностью, прочностью $\mathrm{C}-\mathrm{C}$-связей и малой величиной показателя преломления. Приводятся аналитические, квантово-химические и экспериментальные результаты исследований изменения спектральных, механических параметров, а также угла смачиваемости выбранных модельных неорганических матриц.

Ключевые слова: рельеф поверхности, оптическая керамика, лазерное ориентированное осаждение, углеродные нанотрубки, спектры, угол смачивания.

DOI: 10.21883/PJTF.2019.15.48085.17835

Современное интенсивное развитие научных основ технологий наноструктурирования функциональных материалов способствует открытию новых свойств традиционных композиций и существенно расширяет область их практического применения. Интерес к нанотехнологиям обусловлен тем, что именно в наноразмерной шкале наблюдается значимая корреляция спектральных, механических, рефрактивных и других свойств оптических материалов. При этом известно, что структурированию объема оптических неорганических и органических материалов посвящено довольно большое число научнотехнических публикаций, однако вопрос о влиянии процесса структурирования поверхности модельных матриц на основные физико-химические характеристики изучен недостаточно досконально. Более того, изучение процесса структурирования керамических материалов [1-5] позволяет заменить традиционно используемые кристаллические объемные системы, синтез которых довольно трудоемок. В настоящей работе при использовании инновационного лазерного ориентированного осаждения углеродных нанотрубок на поверхность ряда неорганических оптических кристаллов (на примере оптической керамики КО1 и КО2) приводятся экспериментальные результаты исследования изменения спектральных, механических и гигроскопических свойств материала в целом. Экспериментальные результаты подкреплены аналитическими и квантово-химическими расчетами.

В качестве основного инструмента для осуществления модификации поверхности изучаемых материалов применялся $\mathrm{CO}_{2}$-лазер на длине волны $10.6 \mu \mathrm{m}$ с $p$-поляризованным излучением с мощностью $30 \mathrm{~W}$. В качестве эффективных нанообъектов, ориентированно осаждаемых на поверхность материалов, использовались одностенные углеродные нанотрубки (УНТ) марки SWCNTs type \#704121 с диаметром $0.7 \mathrm{~nm}$, приобретенные в фирме Aldrich Со. Указанные УНТ осаждались на поверхность выбранных материалов - оптических керамик КО1 и КО2 - при варьировании напряженности прикладываемого электрического поля в диапазоне $100-600 \mathrm{~V} \cdot \mathrm{cm}^{-1}$. Часть установки по лазерному ориентированному осаждению УНТ приведена на рис. 1.

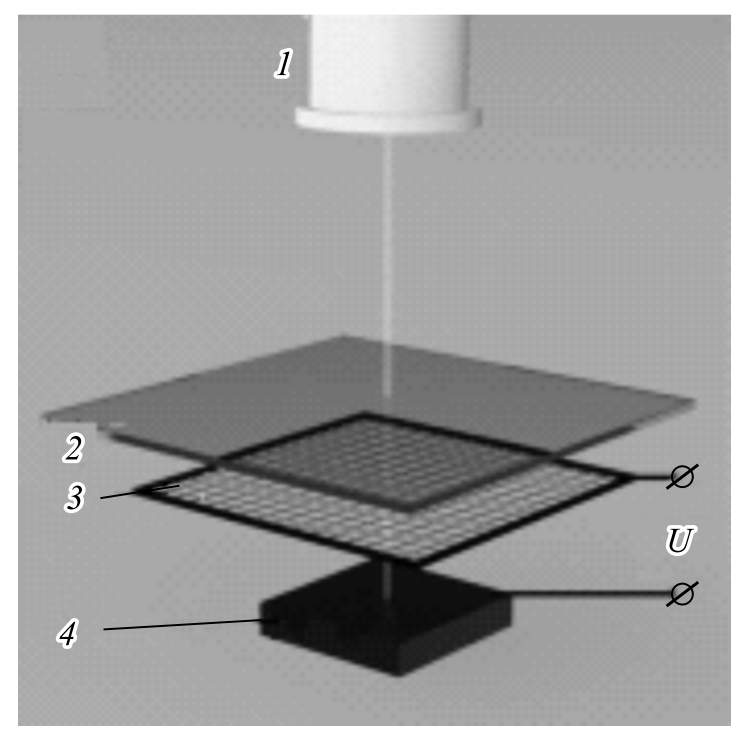

Рис. 1. Экспериментальная схема. $1-\mathrm{CO}_{2}$-лазер, 2 - прозрачная подложка (с креплением для образцов), 3 - металлическая сетка, 4 - углеродная мишень. 
Таблица 1. Изменение пропускания $\mathrm{MgF}_{2}$ и $\mathrm{ZnS}$, структурированных УНТ

\begin{tabular}{c|c|c|c|c}
\hline \multirow{2}{*}{$\begin{array}{c}\text { Выбранное } \\
\text { случайным } \\
\text { образом число } \\
\text { образцов }\end{array}$} & \multicolumn{2}{|c|}{$\begin{array}{c}\text { Пропускание } \mathrm{MgF}_{2} \text { на длине } \\
\text { волны } 125 \mathrm{~nm}, \%\end{array}$} & \multicolumn{2}{c}{$\begin{array}{c}\text { Пропускание } \mathrm{ZnS} \mathrm{на} \mathrm{длине} \\
\text { волны } 2.3 \mu \mathrm{m}, \%\end{array}$} \\
\cline { 2 - 5 } & $\begin{array}{c}\text { до осаждения } \\
\text { УНТ }\end{array}$ & $\begin{array}{c}\text { после } \\
\text { осаждения } \\
\text { УНТ }\end{array}$ & $\begin{array}{c}\text { по осаждения } \\
\text { УНТ }\end{array}$ & $\begin{array}{c}\text { посаждения } \\
\text { УНТ }\end{array}$ \\
\hline 1 & 61.8 & 66.6 & 72 & 73 \\
3 & 63.6 & 69 & 73 & 73.5 \\
4 & 54.5 & 65.8 & 73.5 & 74 \\
5 & 58.1 & 67.5 & 73.5 & 73.8
\end{tabular}

Таблица 2. Результат увеличения микротвердости оптических керамик $\mathrm{MgF}_{2}$ и $\mathrm{ZnS}$

\begin{tabular}{|c|c|c|c|c|c|}
\hline Материал & $\begin{array}{c}\text { Средняя } \\
\text { величина } \\
\text { микротвер- } \\
\text { дости, } \\
10^{9} \mathrm{~Pa}\end{array}$ & $\begin{array}{c}\text { Увеличение } \\
\text { микротвер- } \\
\text { дости при } \\
\text { структуриро- } \\
\text { вании, \% }\end{array}$ & Материал & $\begin{array}{c}\text { Средняя } \\
\text { величина } \\
\text { микротвер- } \\
\text { дости, } \\
10^{9} \mathrm{~Pa}\end{array}$ & $\begin{array}{c}\text { Увеличение } \\
\text { микротвер- } \\
\text { дости при } \\
\text { структуриро- } \\
\text { вании, \% }\end{array}$ \\
\hline $\begin{array}{c}\mathrm{MgF}_{2} \\
\mathrm{MgF}_{2}+\mathrm{YHT}\end{array}$ & $\begin{array}{l}0.3143 \\
0.3322\end{array}$ & $\sim 6$ & $\begin{array}{c}\mathrm{ZnS} \\
\mathrm{ZnS}+\mathrm{YHT}\end{array}$ & $\begin{array}{l}0.2121 \\
0.2231\end{array}$ & $\sim 5$ \\
\hline
\end{tabular}

Видно, что в непосредственной близости от подложки 2 устанавливается металлическая сетка 3 с размером ячейки на уровне $\sim 100 \mu \mathrm{m}$. Расстояние от сетки до подложки регулировалось, в результате чего варьировалась напряженность прикладываемого электрического поля, используемого для ориентирования УНТ.

Выбор для исследования структуры $\mathrm{MgF}_{2}$ определялся довольно широким спектральным диапазоном функционирования от $120 \mathrm{~nm}$ до $8 \mu \mathrm{m} \mathrm{[6],} \mathrm{а} \mathrm{также} \mathrm{обуслов-}$ ливался наличием ранее проведенных аналитических расчетов [7], показавших прямую возможность ковалентной привязки УНТ к поверхности фторида магния, что позволяет эффективно применять данные материалы, в частности, для защитных окон ламп УФ-диапазона, используемых в медицинских клиниках. Выбор для исследования структуры $\mathrm{ZnS}$ определялся широким использованием данного материала в системах солнечной энергетики, полупроводниковой техники, а также в лазерных схемах среднего ИК-диапазона; применение лазерного ориентированного осаждения позволяет увеличить пропускание, прочность и угол смачивания, что расширяет области использования таких матриц.

Спектральные параметры исследовались на инфракрасном фурье-спектрометре ФСМ-1202 и спектрофотометре СФ-26. Механическая прочность определялась на микротвердомере ПМТ-3М (разработка АО „ЛОМО“, Санкт-Петербург). Угол наклона молекул воды на поверхности материалов измерялся с помощью прибора OCA-15E (разработка ООО „ЛабТех“, Москва). Для сканирования поверхности материалов в полуконтактном режиме использовался атомно-силовой микроскоп Solver Next AFM (разработка NT MDT Co., Зеленоград).
Обобщенные данные по спектральным изменениям оптических керамик КО1 и КО2 приведены в табл. 1, а по изменению их микротвердости - в табл. 2.

Отмеченные тенденции изменения спектров пропускания и микротвердости согласовывались с изменением угла смачивания поверхности. Так, угол смачивания для систем $\mathrm{MgF}_{2}$ и $\mathrm{ZnS}$ изменялся от 56 до $81^{\circ}$ и от 102 до $106^{\circ}$ соответственно.

Квантово-химические расчеты подтвердили возможность ковалентной привязки УНТ к поверхности данных матриц, что показано, например, для оптической керамики КО2 на рис. 2. Расчеты были выполнены с помощью метода классической молекулярной динамики, реализованного в программном пакете LAMMPS с учетом математического аппарата [8-10]. Параметры взаимодействия были определены как $\varepsilon=0.011 \mathrm{eV}, \sigma=1.80 \AA$. Рассматриваемая подложка состояла из $\sim 48000$ атомов и имела толщину около $14 \mathrm{~nm}$. Выбранная толщина являлась оптимальной для того, чтобы избежать сквозного проникновения трубки. Моделирование методом молекулярной динамики было проведено при постоянной температуре $300 \mathrm{~K}$. Полное время моделирования составляло 60 ps c шагом в 1 fs. Скорости нанотрубок варьировались от 100 до $600 \mathrm{~m} / \mathrm{s}$, что коррелирует с экспериментальными данными о величине напряженности прикладываемого электрического поля.

Следует заметить, что проведенный анализ данных по корреляции изменений спектральных, прочностных и влажностных параметров изученных матриц хорошо согласуется с аналогичной тенденцией, показанной для гигроскопического кристалла $\mathrm{KBr}$ [11], широко используемого в фурье-спектроскопии. 


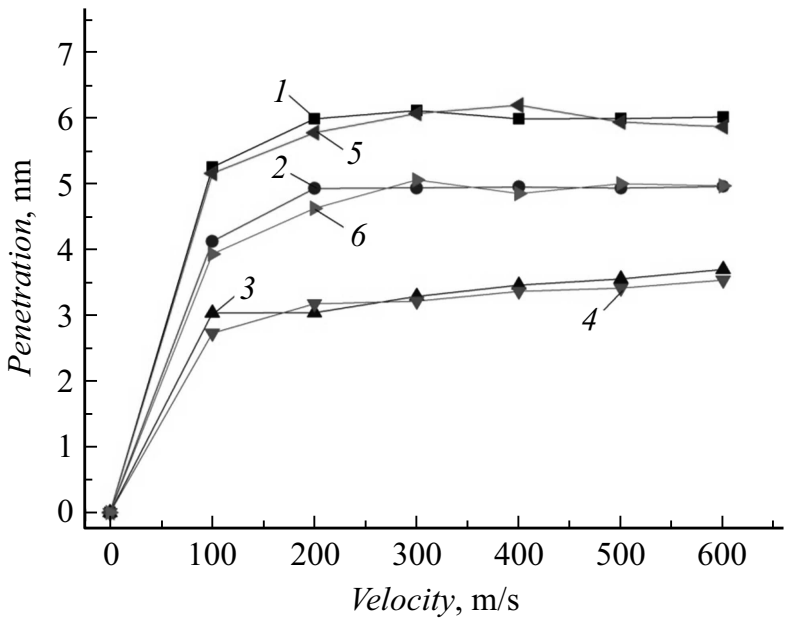

Рис. 2. Глубина проникновения УНТ в приповерхностные слои ZnS с учетом разного диаметра УНТ, а также разной скорости их разлета при осаждении. $1-d=0.64 \mathrm{~nm}$, $2-d=0.94 \mathrm{~nm}, 3-d=2.68 \mathrm{~nm}, 4-d=3.35 \mathrm{~nm}, 5-$ $d=0.64 \mathrm{~nm}\left(20^{\circ}\right), 6-d=0.94 \mathrm{~nm}\left(20^{\circ}\right)\left(20^{\circ}-\right.$ угол, под которым УНТ осаждаются на поверхность).

Анализируя приведенные результаты, можно сделать следующие выводы.

1. Применение лазерного ориентированного осаждения УНТ на поверхность материалов (оптических керамик КО1 и КО2) приводит к

- существенным спектральным сдвигам в УФ-области для фторида магния и небольшим спектральным изменениям в средней ИК-области спектра для сульфида цинка;

- значимым прочностным изменениям как для фторида магния, так и для сульфида цинка;

- изменению угла смачивания для подложек как из фторида магния, так и из сульфида цинка.

Последнее обстоятельство может напрямую способствовать применению структурированных подложек оптической керамики КО1 для ориентирования молекул жидкого кристалла, поскольку получаемый рельеф поверхности вполне пригоден для выравнивания вдоль одного направления жидкокристаллической мезофазы в дисплейных элементах и модуляторах света.

2. Представленное квантово-химическое моделирование на примере оптической керамики КО2 показывает соответствие экспериментальных и расчетных данных. Глубина проникновения УНТ в приповерхностные атомарные слои модельного материала зависит как от диаметра УНТ, так и от скорости их разлета при лазерном осаждении. Результаты могут быть полезны для оптимизации слоев солнечных элементов при необходимости выравнивания рефрактивных параметров.

3. Продемонстрированные лабораторные результаты, естественно, следует и далее подтверждать разными методами, например, с использованием масс-спектрометрического анализа и рамановской спектроскопии, однако уже на данном этапе исследований можно определенно сказать, что лазерные методы имеют существенное преимущество перед традиционными PDV- и CVD-технологиями за счет их бесконтактного и управляемого воздействия, малой потери используемого для осаждения вещества, а также довольно хорошей повторяемости результатов.

Результаты данного исследования частично докладывались на семинаре в ПИЯФ-Курчатовский институт в октябре и ноябре 2017 г. (Гатчина, Санкт-Петербург) и на Кластере конференций в Суздали (1-6 июля 2018 г.).

\section{Благодарности}

Авторы благодарят Д.Г. Квашнина (Национальный исследовательский технологический университет „МИСиС“, Москва) за помощь в проведении квантово-химических расчетов, выражают признательность В.И. Студёнову и П.Я. Васильеву (отдел „Фотофизика сред с нанообъектами“ АО „ГОИ им. С.И. Вавилова“, Санкт-Петербург) за плодотворное обсуждение результатов.

\section{Финансирование работы}

Исследования выполнены при поддержке Федеральной целевой программы „Национальная технологическая база“, проект „Нанокоатинг-ГОИ““ (2012-2015 гг.), а также российско-израильского проекта „Адаптация“ (2017 г.).

\section{Конфликт интересов}

Авторы заявляют, что у них нет конфликта интересов.

\section{Список литературы}

[1] Tjong S.C. Carbon nanotube reinforced composites: metal and ceramic matrices. Weinheim: WILEY-VCH Verlag, 2009. $242 \mathrm{p}$.

[2] Osipkov A.S., Bashkov V.M., Belyaeva A.O., Stepanov R., Mironov Y.M., Galinovsky A.L. // IOP Conf. Ser.: Mater. Sci. Eng. 2015. V. 74. P. 012013.

[3] Gan L., Park Y.-J., Zhu L.-L., Kim H.-N., Ko J.-W., Kim H.-D. // J. Eur. Ceram. Soc. 2018. V. 38. N 11. P. 4064 4069. https://doi.org/10.1016/j.jeurceramsoc.2018.04.056

[4] Liao N., Jia D., Yang Z., Zhou Y., Li Y., Jia X. // Mater. Sci. Eng. A. 2018. V. 710. P. 142-150.

[5] Jiang Y., Jiang B., Zhu Q., Jiang N., Zhang P., Chen S., Hu X., Zhang G., Fan J., Su L., Li J., Zhang L. // J. Eur. Ceram. Soc. 2018. V. 38. N 5. P. 2404-2409.

[6] Рипан Р., Четяну И. Неорганическая химия. Т. 1. Химия металлов. Пер. с рум. М.: Мир, 1971. 561 с.

[7] Kamanina N.V., Bogdanov K.Yu., Vasilyev P.Ya., Studeonov V.I. // J. Opt. Technol. 2010. V. 77. N 2. P. $145-147$.

[8] Plimpton S. // J. Comput. Phys. 1995. V. 117. N 1. P. 1-19.

[9] Tersoff J. // Phys. Rev. B. 1989. V. 39. N 8. P. 5566-5568.

[10] Kvashnin D.G., Sorokin P.B. // J. Phys. Chem. Lett. 2015. V. 6. N 12. P. 2384-2387.

[11] Kamanina N.V., Likhomanova S.V., Kuzhakov P.V. // Sensors. 2018. V. 18. N 9. P. 3013 (1-8). 